\title{
The Concept Image of Students and Teachers about the Equal Sign
}

\author{
Lia Ardiansari*, Didi Suryadi, Dadan Dasari \\ Department of Mathematics Education, Universitas Pendidikan Indonesia, Jl. Dr. Setiabudhi No. 229, \\ Bandung, West Java, 40154, Indonesia
}

Received September 9, 2020; Revised October 15, 2020; Accepted November 11, 2020

\section{Cite This Paper in the following Citation Styles}

(a): [1] Lia Ardiansari , "The Concept Image of Students and Teachers about the Equal Sign," Universal Journal of Educational Research, Vol. 8, No. 12, pp. 6751 - 6764, 2020. DOI: 10.13189/ujer.2020.081240.

(b): Lia Ardiansari (2020). The Concept Image of Students and Teachers about the Equal Sign. Universal Journal of Educational Research, 8(12), 6751 - 6764. DOI: 10.13189/ujer.2020.081240.

Copyright $\subseteq 2020$ by authors, all rights reserved. Authors agree that this article remains permanently open access under the terms of the Creative Commons Attribution License 4.0 International License

\begin{abstract}
The teacher as an educator plays an important role in the process of forming a concept image of students about the equal sign in learning mathematics. Teachers must have an equal sign meaning in accordance with the capacity, learning experience, and knowledge which is a source for them to compile a certain didactic design. The didactic design that has been compiled becomes a learning environment that triggers students' mental perceptions and actions so that a concept image of the equal sign is formed. This study aims to explore teachers' understanding and confirm that the concept image formed by these students may be the impact of the learning process with didactic designs that have been compiled by the teacher. The investigation was conducted qualitatively using a case study approach involving 6 teachers and 55 elementary and middle school students. The data collection methods included teacher questionnaires and interviews with two selected teachers, as well as students answering a series of questions then six students were deliberately selected to be interviewed based on their responses. The results show that the teachers' concept images about the equal sign are generally difficult to say that they already have a well-developed relational view, in addition, they lack the knowledge and skills to identify, anticipate, reduce, or correct students' misconceptions about the equal sign. As a result, the majority of students do not have a concept image about the equal sign that matches the scientific conception that should be.
\end{abstract}

Keywords Algebraic Thinking, Concept Image, Equal Sign, Zone of Concept Image Differences

\section{Introduction}

An important part of mathematics that is used in all kinds of calculation of equations more than any other symbol is the equal sign. Students' understanding of the equal sign is one of the important foundations for their success in learning mathematics because there is no subject matter in mathematics does not use it (Carpenter, et al., 2003; Jones, et al., 2012; Kieran, 1981; Knuth, et al., 2006; Rittle-Johnson, et al., 2010; Stephens, et al., 2013). Although the equal sign is a very important concept for understanding mathematics at all levels of school mathematics, the meaning of 'equal' is a complex idea and difficult to understand for most students (Alibali, 2007; Kieran, 1981). Several researchers (e.g, Darr, 2003; Falkner, Levi and Carpenter, 1999) report that one of the main stumbling blocks for students as they move from arithmetic to algebra is their understanding of the equal sign because the meaning of the equal sign is rarely taught to students explicitly (Jones, et al., 2012; Li, et al., 2008).

This understanding involves subjective mental action so that each individual can have a different meaning according to their learning experience (Kieran, 1981; McNeil, et al., 2006; Prediger, 2010; Radford, 2000; Sherman \& Bisanz, 2009). The understanding obtained by students from previous experiences forms a concept image that can be repeated and consistent in the long term (Knuth et al., 2006; McNeil \& Alibali, 2005). Knowledge gained from initial experience if it does not match the information 
found in future efforts will have a 'top-down' effect so that early learning difficulties become the cause of learning difficulties later in life (Bruner, 1957; McNeil \& Alibali, 2004, 2005; Rumelhart, 1980) that students' errors in interpreting the meaning of the equal sign as in the early grades can be the cause of learning difficulties at a later date even at the higher education level (Baiduri 2015; Best, McRoberts, \& Goodell, 2001; Flege, Yeni Komshian, \& Liu, 1999; Knuth et al., 2006; McNeil \& Alibali, 2005).

Many researchers in various countries have explored learners' understanding of the equal sign in primary, secondary, and college schools (eg, Alibali, et al., 2007; Baiduri, 2015; Carpenter, et al, 2005; Fuchs, et al., 2014; Kindrat \& Osana, 2018; McNeil, et al., 2006). This suggests that understanding the equal sign has become the focus point of reform and research efforts in mathematics education as a proven "problem" that is strong and long-term for primary, secondary, and even college students. Elementary students still see the equal sign as an operator instead of a relational symbol (Hattikudur \& Alibali, 2010; Kiziltoprak \& Kose, 2017; Knuth, et al., 2008; McNeil \& Alibali, 2005). Junior high school students are in a transition period from arithmetic thinking to algebraic reasoning (Kieran, 1981), wherein this transition students have to make many adjustments even students who are quite proficient in arithmetic (Kilpatrick, et al., 2002). In addition, at this transitional stage according to Kieran (1981), they are in the intermediate stage of an 'equal sign' as a computational sign and receive the equal sign as a symbol of equality. The principle of mathematical equality serves as the main link between arithmetic and algebra (Mattews, et al., 2010). Transformation operations and the meaning of the equal sign in arithmetic as equality can underlie "algebraic manipulation".

This article reports on a small-scale study conducted to investigate the extent to which grade 6 primary and grade 7 junior secondary students understood the equal sign. It also investigates the understanding of primary and secondary school teachers about the equal sign, confirming that the concept image formed in students may be the impact of the learning process with didactic designs that have been compiled by teachers as educators about this concept. Teachers play an important role in the process of interpreting the equal sign with students in mathematics learning. One of their roles is compilers of didactic learning designs which become learning environments that trigger perceptions about and actions on the didactic design. Therefore, teachers must have a concept image of the meaning of the equal sign according to their capacity, learning experience, and knowledge which are sources for them to compile a certain didactic design. In particular, it attempts to answer the question whether the teacher's interpretation of the equal sign might help them prevent misunderstandings from developing early in their students as well as helping them form correct conceptions.

\section{Theoretical Framework}

\subsection{The Zone of Concept Image Differences (ZCID)}

Judging from current textbooks and teaching practices, teachers at all grade levels tend not to be able to see mathematics as a conceptual tool needed to construct mathematical objects that are required cognitively, pedagogically, and epistemologically, but merely as "subject matter" (for example, definitions, theorems, proofs, problems, and solutions). Students need reasoning that involves a lot of mental actions such as interpreting, guessing, concluding, proving, explaining, arranging, generalizing, applying, predicting, classifying, looking for, and solving problems in learning mathematics. Certain cognitive products of the mental actions performed by students will result in a way of understanding (WoU). When a certain symbol is given, for example, an equal sign $(=)$, the resulting interpretation can vary according to the way of understanding the symbol, context, and experience of each individual. This interpretation can be considered true or false. Conversely, way of thinking (WoT) is a cognitive characteristic of mental action. Such characteristics are invariably deduced from observing the mode of understanding which is the cognitive product of mental action. For example, a teacher who follows students' mathematical behavior may conclude that a student's interpretation of the equal sign may be characteristically inflexible, without quantitative references, or, in connection with other concepts. The way of understanding (WoU) and the way of thinking (WoT) that results from mental action is what underlies the formation of one's conceptual image. The term concept image describes the total cognitive structure associated with a particular concept covering all mental images and related properties and processes (Tall and Vinner, 1981). The pedagogical consequence of this fact is that the way of understanding should not be treated by the teacher as an absolute universal entity that is shared by all students, because it is inevitable that every student tends to have a special way of understanding that depends on himself or his experiences and backgrounds. Together with helping students develop desired ways of understanding, the teacher's goal should be to increase interaction among students so that their different ways of understanding are compatible with each other and with the mathematics community (Harel, 2008).

Efforts to help students find the desired way of thinking should be made in the elementary because the formation of the desired way of thinking is not easy and the unwanted way of thinking that has been formed is difficult to let go of. In general, the equal sign was introduced in the mathematics learning process in schools since students learned arithmetic in elementary. Therefore, how equal sign is interpreted and taught in elementary is an important foundation for the formation of a concept image that exists 
in students. The concept image in each student certainly varies depending on the capacity, learning experience, and knowledge they have, so it is not necessarily according to the scientific conception that should be. The gap that occurs between concept images and scientific conception is one of the realities of the Zone of Concept Image Differences (ZCID) (Suryadi, 2019) which is illustrated in Figure 1.

Figure 1 shows a learning environment that is formed from a series of didactic designs that have been made by the teacher before starting learning in class. This clearly shows that the task of the teacher in the teaching and learning process in the classroom is to create a learning environment that is expected to encourage mental actions and then summarize them into new mental objects that must be studied from a didactic point of view so that the learning process becomes complex. The complexity of the didactic situation has the potential to create a pedagogical situation, namely student-student interactivity and teacher-student relations which are equally important to study. Therefore, the didactic and pedagogical relationship cannot be viewed as partial but needs to be fully understood. In addition, a teacher in addition to having a correct conceptual image related to the material being taught also needs to anticipate various possible responses that require both didactic and pedagogical in such a way that the dynamics of changes in didactic and pedagogical situations can be created according to the needs, capacities, and acceleration of the learning process (Suryadi, 2019).

Based on Figure 1, it can be seen that concept image of teachers based on their experience, prior knowledge, and learning resources is the starting point for the biggest control informing students' concept images. Concept images that are incompatible with scientific conception indicate the existence of a Zone of Concept Image Differences (ZCID), namely the gap that occurs between concept images in students as a result of learning experiences and learning resources that become a reference in the learning environment that occurs due to a certain didactic series that is not according to the scientific conception that should be (Suryadi, 2019). The gap between students' concept images and scientific conception causes students to have immature conceptual imagery, resulting in 'misconceptions' that are resistant to change, resulting in entrenched misunderstandings (Vermeulen and Meyer; 2017).

\subsection{The Equal Sign and the Views of the Equal Sign}

One of the most important concepts for developing algebraic thinking in school students is the mathematical equation (Knuth, et al, 2006; McNeil, et al., 2011). The equal sign is important because it is the basis for understanding equations where equations are the essence of understanding algebra, therefore a correct understanding of the equal sign has an important urgency for success in algebra (Banerjee, 2011; Filloy and Rojano, 1989; Kieran, 1981; Oksuz, 2007). The understanding of equations cannot be separated from the concept of the equal sign so that the concept of the equal sign and the concept of equality cannot be separated (Baiduri, 2015). Some researchers define equations as the relationship between two quantities that are equal and interchangeable (Banerjee, 2011; Darr, 2003; Filloy and Rojano, 1989; Kieran, 1981; Mann, 2004; Sherman \& Bisanz, 2009). The definition of equations must be well understood by students so as not to become a major stumbling block for them moving from arithmetic to algebra (Falkner, Levi \& Carpenter, 1999; Kieran, 1981; Oksuz, 2007). The capacity to operate numerically, understanding operational laws, the relational meaning of the equal sign, inserting nonstandard equations, and the concept of variables can support a formal understanding of equations (Fuchs, L.S. et al., 2014). A formal understanding of these equations involves knowledge of numbers, measurements, and expressions that can be represented in various ways that are the same and can be exchanged as well as an understanding of the equal sign as a relational symbol, namely stating an equality relationship on both sides of the equal sign (Kieran, 1981; Knuth, et al., 2006; Mattews, 2010; McNeil, Fyfe, \& Dunwiddie, 2015).

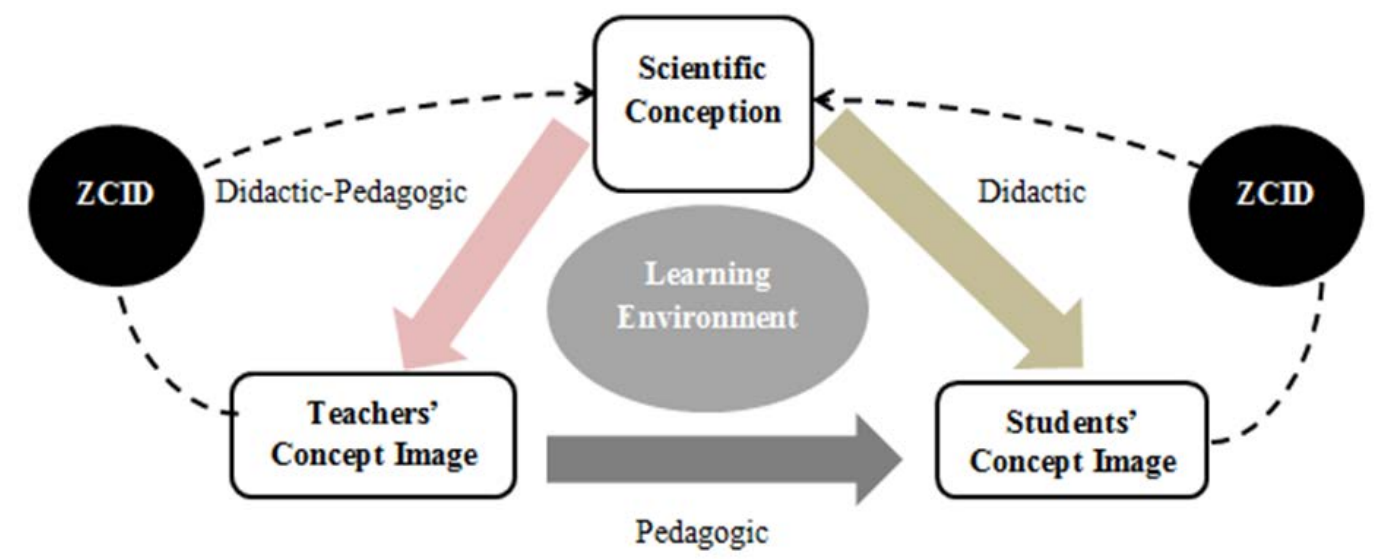

Figure 1. Zone of Concept Image Differences (ZCID) 
The meaning of the equal sign $(=)$ in mathematics expresses the relationship of identity, namely, 'is equal to', 'is the same as' or 'is identical to'. They all refer to the specific relationship of the equivalent relation. That is, equality is different in meaning from equivalence because there are other equivalent relations that do not refer to the same relationship. Even though there are differences, equivalency and identity do share some of the same characteristics, namely, identity (equality) is a certain equality relationship in the sense of reflective, transitive, and symmetrical (Mirin, 2019).

The equal sign in a mathematical point of view is not a command to do something but a sign of equality. Equality is about similarity, whereas an equation is a special mathematical design that describes the relationship between expressions with the same value. The equality relationship defined by the equal sign makes the equation possible to be manipulated and rearranged so that new ways of expressing equality can be constructed and unknown values can be found (Darr, 2003). Furthermore, an expression is defined by Powell (2012) as a combination of numbers and operations without the equal sign (e.g. $9: 3 ; 1+1+4 ; y \times 6)$. Meanwhile, a mathematical statement in which the equal sign is used to show the equivalence between a number or expression on one side of the equal sign with a number or expression on the other side of the equal sign is called an equation (Powell, 2012). Every equation has two sides, namely the left and right sides where the equal sign is the dividing point between the sides. Mathematical equations are equations involving an equal sign where there is zero or one variable (e.g., $9=6+3 ; 9=x+3)$, whereas algebraic equations use two or more variables (e.g., $x-3=y$ ).

Prediger (2010) provides six different interpretations of the equal sign which he grouped into three categories, namely: 1) operational, which stands for the asymmetric use of 'operation equals answer', for example 24:6$3=1$ or $\left.f^{\prime}(x)=\left(3 x^{2}\right)^{\prime}=6 x ; 2\right)$ relational, focuses on the symmetric use of the equal sign. This relational category has four subcategories, namely (a) symmetric arithmetic identity is a symmetric use of the equal sign in an arithmetic context which expresses general relationships and numerical identities that are trivial to compute in one direction, but difficult to find out in the other direction, for example $5+7=7+5$ or $19=10^{2}-9^{2}$; (b) formal equivalence describing equivalent terms, for example $x^{2}+x-6=(x-2)(x+3)$ or $(a-$ b) $(a+b)=a^{2}-b^{2}$; (c) conditional equations characterizing unknowns, for example solving $x^{2}=$ $-x+6$; (d) contextual identities in formulas, for example the Pythagorean theorem $a^{2}+b^{2}=c^{2}$; and 3) specification, where identity is stated in the definition, for example $m=1 / 2(a+b)$.

Based on this description, it appears that the equal sign has a very rich diversity of interpretations where this diversity is important to include in the global characterization of basic algebra. The specificity of the context of meaning can lead to a shift in meaning that lasts in the long run. In fact, to be successful in mathematics students must be able to switch between different meanings according to the needs of the context (Prediger, 2010). Changes in the meaning of the equal sign not only represent obstacles in the learning process but also represent important characteristics and strengths of mathematics.

Weak understanding of the same relationship is described by the word 'operational' (Mirin, 2019). In some literature, operational understanding is expressed as seeing an equal sign involving the performance of an operation. Many writers give an 'operational' view as a false or unproductive understanding and contrast with the relational view that is anything that is not an operational view. This relational (non-operational) view involves looking at the equal sign which states the equivalent relationship (Denmark et al., 1976; Kieran, 1981); the relationship between two quantities (Knuth et al., 2008; McNeil and Alibali, 2005); the relationship between the same values of two numerical expressions (Oksuz, 2007; Seans-Ludlow \& Walgamuth, 1998). According to Mirin (2019), seeing the equal sign as an equivalent relationship is responsible for a way of thinking where, for example (i) $5=2+3$, (ii) $2+3=4+1$, and (iii) $5=5$ is not a violation rules, but rather replaceability. Let " $="$ be an equivalence relationthe symmetry, e.g. $2+3=5$ is $5=2+3$. Similarly, it follows from the reflexivity that $5=5$. Thus (i) and (iii) are no longer a violation of the rule. Conclusion (ii) can easily be obtained by means of symmetry and transitivity, i.e. $2+3=5$, where symmetry is obtained as $5=4+1$. Hence, it follows from the transitivity that $2+3=4+1$.

Students may realize that the equal sign represents equality, although this recognition still depends on the context in which the sign is presented or depends on the operator's interpretation when presented with a symbolic expression (McNeil \& Alibali, 2005; Seo \& Ginsburg, 2003; Sherman \& Bisanz, 2009). If the effect of context on understanding the equal sign extends to situations where children have to solve problems, then the accuracy should be higher for non-symbolic problems than on symbolic problems (Seo \& Ginsburg, 2003; Sherman \& Bisanz, 2009). Children can detect a-b-a patterns and respond by solving non-calculative patterns such as identity problems $(\mathrm{a}+\mathrm{b}=\mathrm{a}+\ldots)$ and commutative problems $(\mathrm{a}+\mathrm{b}=\mathrm{b}+\ldots)$. Conversely, a combination problem such as $(\mathrm{a}+\mathrm{b}=\mathrm{c}+\ldots)$ will be difficult to solve correctly without using sort of arithmetic procedure but can be solved easily if the student recognizes that the two expressions on both sides of the equal sign have the same value and that terms $b$ and c must be combined. So not all equality problems have the same demands on problem solvers.

\section{Research Methods}

The studies in this article are intended to answer the 
following research questions.

a. What is the concept image of the students in grades 6 and 7 about the equal sign?

b. What misconceptions do grade 6 and 7 students have about the equal sign?

c. What is the concept image of elementary and junior high school teachers about the equal sign?

This research is a qualitative case study with some quantifiable results. There are two schools that are the location of our research, namely elementary and junior high schools in the relatively prosperous suburb of Probolinggo - East Java, Indonesia. The language of learning and teaching in schools is Indonesian, as the mother tongue of most students. In general, parents are very supportive and involved in their children's education. They are schools that are in the best cluster in the city of Probolinggo, East Java. The teachers are very dedicated to strict discipline codes adhered to. In general, students are motivated and want to achieve. Four elementary teachers and two grade 7 mathematics teachers participate as our respondents. The objectives of the study were explained and their confidentiality guaranteed so that they agreed to participate in fill out the questionnaire and then return it. However, only two people agreed to be interviewed. During the interview, the two teachers were willing to openly share their knowledge and experiences.

The sample consisted of 35 grade 6 (aged 11-12) from two classes and 20 grade 7 (aged 13-14). The grade 6 students were selected for the study because they were in the final grade before entering junior high school and we believe that, at this stage of the school, the basics of arithmetic should be well established and misunderstandings must be proven and identifiable. While grade 7 was chosen because they were in the early class entering algebra.

The data collection instrument consisted of a teacher questionnaire, student-written assignments, as well as a one-on-one interview guide with two students in grades 6 and four students in grades 7 who were deliberately selected based on their responses in completing written assignments. All instruments used are written in Indonesian. The teacher's questionnaire aims to explore the conceptual description that teachers have about the equal sign. However, the interview lasted for about 10 minutes aimed at providing the opportunity for teachers to confirm and discuss their responses in the questionnaire how in their view the equal sign could be used, their observations about the use of the equal sign with students, and their opinions regarding why student misunderstandings occurred and how to attempt it. Prevention that can be done so that these misunderstandings can be corrected and minimized in the next generation. All interviews (teacher and student) were audio-recorded and then transcribed. A content analysis methodology (Du Plooy-Cilliers, Davis \& Bezuidenhout, 2014) was followed, and coding was used to identify themes emerging from the transcript. The responses to the students' written assignments were coded, tabulated, and analyzed to determine which category the students had about the equal sign. The feedback obtained during the student interviews was compared with the results of the written assignments to establish commonalities. The questions in the student's written assignments and the teacher questionnaire were selected from a selection of the empirical research literature to cover a broad spectrum of questions with the potential to reveal conceptual images and student and teacher misconceptions about the equal sign. Construction map Matthews et al. (2012), Prediger (2010), and Vermeulen \& Meyer (2017) design an appropriate framework to interpret students' conceptual depictions and misconceptions about the equal sign, and therefore used in research conclusions.

\section{Findings and Discussion}

\subsection{Concept Image of Students about the Equal Sign}

The findings of students' concept drawings were obtained based on students' answers in written tasks, transcripts of interviews with six students, and results of the analysis of mathematics textbooks that they used as learning materials in class. The data were collected through triangulation methods, namely tests, interviews, and document analysis. A total of 55 students participated in the written test about the equal sign. Data collection begins with a written test for elementary and junior high school students aged 11-14. The student answer sheets were analyzed and then explored through interviews with six selected students. Some previous researchers mentioned that elementary school students had knowledge of the equal sign as a signal to count, a sign that usually appears at the end of a numeric expression and there is only one number after it (Falkner et al., 1999; Prediger, 2010; Vermeulen \& Meyer, 2017). This written test aims to explore the concept of an equal sign in their thinking, classify the types of their misunderstanding, confirm the cause and facilitate the formation of a relational concept image of the equal sign. Students' conceptual image are categorized into three operational, relational, and specification categories as introduced by Prediger (2010). Table 1 summarizes the quantitative results of the students' written assignments. 
Table 1. Summary of quantified results from 55 students who participated in writing task about the equal sign

\begin{tabular}{|c|c|c|c|c|}
\hline $\begin{array}{c}\text { Type of } \\
\text { Students’ } \\
\text { Concept Image }\end{array}$ & Questions & $\begin{array}{l}\text { Total Number of } \\
\text { Students who } \\
\text { Answered the } \\
\text { Questions } \\
\end{array}$ & $\begin{array}{c}\text { Number of } \\
\text { Students who } \\
\text { Demonstrated the } \\
\text { Category }\end{array}$ & $\begin{array}{c}\text { Percentage (\%) of } \\
\text { Students who } \\
\text { Demonstrated the } \\
\text { Category }\end{array}$ \\
\hline \multirow{4}{*}{ Operational } & $\begin{array}{c}\text { Question } 1 \\
19= \\
\end{array}$ & 55 & 55 & 100 \\
\hline & $\begin{array}{c}\text { Question } 2 \\
-=12-17\end{array}$ & 54 & 54 & 100 \\
\hline & $\begin{array}{c}\text { Question } 3 \\
12+2=14: 2=7\end{array}$ & 55 & 55 & 100 \\
\hline & $\begin{array}{l}\text { Question } 4 \\
7 \frac{3}{4}-4 \frac{1}{8}=\frac{6}{8}-\frac{1}{8}=\frac{5}{8}=3 \frac{5}{8}\end{array}$ & 50 & 50 & 100 \\
\hline \multirow{4}{*}{ Relational } & $\begin{array}{l}\text { Question } 1 \\
3+\square=4+12\end{array}$ & 55 & 6 & 10,9 \\
\hline & $\begin{array}{c}\text { Question } 2 \\
(17+4): 3=\square+4\end{array}$ & 55 & 5 & 9,09 \\
\hline & $\begin{array}{c}\text { Question 3 } \\
8+(3 \times 8)=(5 \times 8)-8\end{array}$ & 55 & 5 & 9,09 \\
\hline & $\begin{array}{c}\text { Question 4 } \\
\text { Jika } 2 \times \square+\mathbf{1 5}=\mathbf{3 1}, \\
\text { maka } 2 \times \square+\mathbf{1 5 - 9 = 3 1 - 9}\end{array}$ & 51 & 4 & 7,84 \\
\hline \multirow[b]{2}{*}{ Spesification } & $\begin{array}{c}\text { Question 1 } \\
\text { If } A=\{2,6,7,6\} \text { and } B=\{2,6,7\} \text { then } A=B\end{array}$ & 53 & 3 & 5,66 \\
\hline & $\begin{array}{l}\text { Question } 2 \\
\text { Lisa started a problem with a one-digit number. } \\
\text { She multiplied the number by } 2 \text {, added } 6 \text {, } \\
\text { divided by } 3 \text { and subtracted } 1 \text {, and got the same } \\
\text { number he started with. What was the number } \\
\text { Lisa started with? (Show all working out) }\end{array}$ & 49 & 0 & 0 \\
\hline
\end{tabular}

From Table 1 it is clear that relatively few students show the relational and specification categories, almost all students still have a conceptual description of the equal sign in the operational category. These results are similar to those found by many of the other studies referred to earlier.

All students in this study saw the sign as a result of left-to-right surgery. When interviewed, they generally interpreted " $19=$ +25 " as " 19 plus 25 points of result". They ignore the location of the equal sign in the math sentence. According to Falkner et al. (1999), this occurs because in elementary schools the equal sign usually appears at the end of numeric expressions and only one number appears after it that when they are given an expression that is not as they usually do, they know what to do with a calculation but are not sure how. This can also occur as a result of the repetitive nature of certain arithmetic tasks, where students count expressions then write their answers immediately after the equal sign
(Meyer, 2016). Questions 3 and 4 are the form of string operations. The two teachers interviewed in this study, generally, the form of string operations such as $12+2=14$ : $2=7$ was considered correct according to students in grades 6 and 7 for years. Students do not see that $12+2$ and $14: 2$ as one unit. Those students clearly understand that they can partition the numbers in the operation. According to Tilley (2011), this is a common misuse of the equal sign in that students solve calculations mentally by breaking them into steps that can be managed arbitrarily. Of course, this shows that the equal sign has not been seen as a sign indicating that the value of the left and right sides of the equal sign is the same.

The term "relational" accurately describes understanding because what is embedded in meaning is a cognitive relationship or schema, in which background knowledge and related concepts are linked in the person's thinking (Meyer, 2016). Therefore, relational understanding refers 
to an integrated and functional understanding of mathematical ideas that can be demonstrated in a reflective thinking mode such as combining two rules without really knowing why they work (Kilpatrick, et al. 2002). Based on Table 1, it appears that there are still many students in this study who view the equal sign as an indicator of computational results rather than an expression of relational equality. There are 36 students filling 1 in the box as the answer to question $3+\square=4+12$. They ignore the " $+12 "$ in the equation. When asked in the interview, two students confirmed the answer to "Oh yes, it means $3+1=4+12=16 "$. The other 11 students answered 19 as the contents of the box which is the result of $3+4+12$. It appears that the students use all the numbers in their attempt to solve the equation which is indicative of the operational viewpoint to find the answer after the equal sign.

In this specification category, only 3 students that are grade 7 were able to answer correctly that $\mathrm{A}=\mathrm{B}$ in question 1 was something that had been defined. In question 2, given a number which is defined as an unknown number, consisting of only one digit which is multiplied by 2 , then added by 6 , divided by 3 , then subtracted by 1 will produce the unknown number itself. A total of 49 students answered the questions, even though they actually did not know the meaning of the questions well so they made arbitrary string arrangements such as the following interview excerpt.

Researcher: "explain how you got the answer?"

Student: "I start from $7 \times 2$ is 14 plus 8 to 22, then divided by 3, so 7 minus 6 is 1 "

Researcher: "Where do you get 7 to start with?"

Student: "arbitrarily, ma'am ..."

This also shows that he is less proficient in skills in carrying out procedures flexibly, accurately, efficiently, and precisely (Kilpatrick et al., 2002).

\subsection{Misconceptions of Students about the Equals Sign}

Discussions about students misunderstandings about the equal sign found from the results of written tasks and interviews are identified into three categories, namely closure, using all the numbers in the equation, and string operations. Students' misunderstanding is categorized as' closure 'if they assume that the equal sign signifies the operation on the left side and the answer comes after an equal sign such as $4+6=\ldots+5 ; \ldots=10$ (Blanton, 2008; Meyer, 2016). There are some students who try to use all the numbers in the equation in an attempt to find the answer to the equation such as $10+2=$ $+5 ; \ldots=12$. The misconception is categorized as 'using all the numbers in the equation'. When an equation is solved by using the 'arbitrary' of the equal sign by breaking it into manageable steps such as $16-4=$ $12+5=17$, such steps fall into the category of 'string operations' (Tilley, 2011). All of these categories represent the operational view of the equal sign. A summary of the number of students who experienced misunderstandings about the equal signs in all categories is presented in Table 2.

Table 2. Summary of Students' Misconceptions

\begin{tabular}{|c|c|c|c|c|c|c|}
\hline \multirow[b]{2}{*}{ Questions } & \multirow{2}{*}{$\begin{array}{c}\text { Total } \\
\text { Number of } \\
\text { Students } \\
\text { who } \\
\text { Answered } \\
\end{array}$} & \multirow{2}{*}{$\begin{array}{c}\text { Total } \\
\text { Number of } \\
\text { Students who } \\
\text { Answered } \\
\text { Correctly } \\
\end{array}$} & \multirow{2}{*}{$\begin{array}{c}\text { Total } \\
\text { Number of } \\
\text { Students who } \\
\text { Answered } \\
\text { Incorrectly } \\
\end{array}$} & \multicolumn{3}{|c|}{ Type of Misconceptions } \\
\hline & & & & Closure & $\begin{array}{l}\text { Using All the } \\
\text { Numbers in } \\
\text { the Equation }\end{array}$ & $\begin{array}{c}\text { String } \\
\text { Operations }\end{array}$ \\
\hline $19=\ldots+25$ & 55 & 18 & 37 & 20 & 11 & 6 \\
\hline$\ldots=12-17$ & 54 & 15 & 39 & 0 & 29 & 10 \\
\hline $12+2=14: 2=7$ & 55 & 0 & 55 & 0 & 0 & 55 \\
\hline $7 \frac{3}{4}-4 \frac{1}{8}=\frac{6}{8}-\frac{1}{8}=\frac{5}{8}=3 \frac{5}{8}$ & 50 & 3 & 47 & 0 & 2 & 45 \\
\hline $3+\square=4+12$ & 55 & 6 & 49 & 36 & 11 & 2 \\
\hline$(17+4): 3=\square+4$ & 55 & 5 & 50 & 26 & 17 & 7 \\
\hline $8+(3 \times 8)=(5 \times 8)-8$ & 55 & 5 & 50 & 0 & 32 & 18 \\
\hline $\begin{array}{c}\text { If } 2 \times \square+15=31, \\
\text { then } 2 \times \square+15-9=31-9\end{array}$ & 51 & 4 & 47 & 35 & 5 & 7 \\
\hline $\begin{array}{c}\text { If } A=\{2,6,7,6\} \text { and } B=\{2,6,7\} \\
\text { then } A=B\end{array}$ & 53 & 3 & 50 & 28 & 22 & 0 \\
\hline $\begin{array}{l}\text { Lisa started a problem with a one-digit } \\
\text { number. She multiplied the number by } \\
2 \text {, added } 6 \text {, divided by } 3 \text { and subtracted } \\
1 \text {, and got the same number he started } \\
\text { with. What was the number Lisa } \\
\text { started with? (Show all working out) }\end{array}$ & 49 & 0 & 49 & 0 & 0 & 49 \\
\hline Total & 532 & 59 & 473 & 145 & 129 & 199 \\
\hline Percentage (\%) & 100 & 11,09 & 88,91 & 27,25 & 24,25 & 37,41 \\
\hline
\end{tabular}


From Table 2, it can be seen that 'string operations' is a category of the misconception that is mostly experienced by students regarding the equal sign, which is $37.41 \%$. According to Meyer (2016), Risch (2014), and Sewell (2002) many school students tend to perform arbitrary operations, do not require mental action, do not reconstruct pre-existing knowledge, and feel quite satisfied with what is always they know.

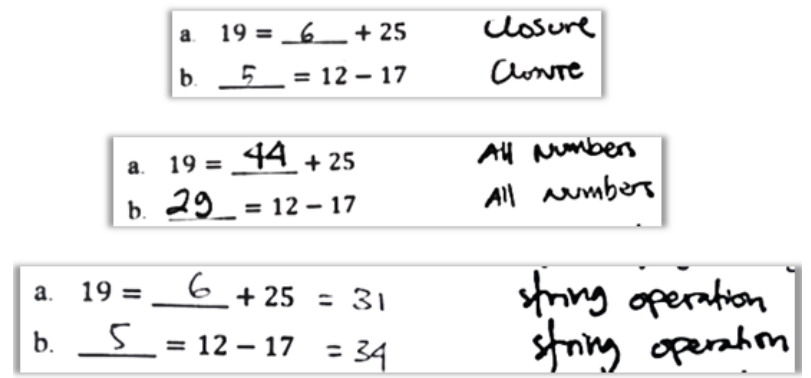

Figure 2. Examples of Students' Misconceptions on Operational Questions 1 and 2

Question 19 = +25 is the question that has the highest number of correct answers compared to other questions. Students who answer incorrectly with the misconception of the type of "closure" often ignore the position of the equal sign in the equation. They tend to read the equation from left to right which is '19 plus how much is 25 ' and not vice versa. Likewise questions _ $=12-$ 17 , namely ' 17 minus 12 '. Students with the misconception "using all the numbers in the equation" focus on the result so that they only pay attention to the addition sign "+" but ignore the position of the equal sign. Meanwhile, students with the 'string operations' misconception tend to expand the problem by adding another equal sign to the right and then writing down the result. It seems that this group of students with this misconception is used to seeing the answers on the right side of the equal sign. Figure 2 presents examples of students' answers to operational questions 1 and 2 for each type of misconception.

Relational category questions 1 to 4 involve more complex number sentences because they require multiplication, division, and the conceptual representation that the equal sign represents equality. In questions 3 and 4 it is a true/false question. Students are asked to rate whether the equation is 'True' or 'False' without avoiding it with a calculator. In question 3, many students did not understand what to do because they thought this number sentence was not a question to solve. They gave the reason that there was no _ sign or $\square$ what they usually recognized as a marker for writing answers. So when asked how they can make the conclusion that the numeric sentence is correct. A students answered that "the mixed calculation is correct because the number 8 (to the left of the equal sign) is a mixture $(5 \times 8) "$ ". It's a 'closure'. Meanwhile, one of the other students who struggled with all the numbers to get a conclusion, answered that the equation was wrong 'because the results are not the same' namely the left side was $8+3+8=19$ while $5+8+8=48$. The student only focuses on the numbers in the equation while the operation is ignored. The student with the operation string category also concluded that the equation was wrong because the left side was 88 and the right side was 32 . He ignored the parentheses and the order of operations in solving mathematical calculations. Figure 3 provides examples of these misconceptions.
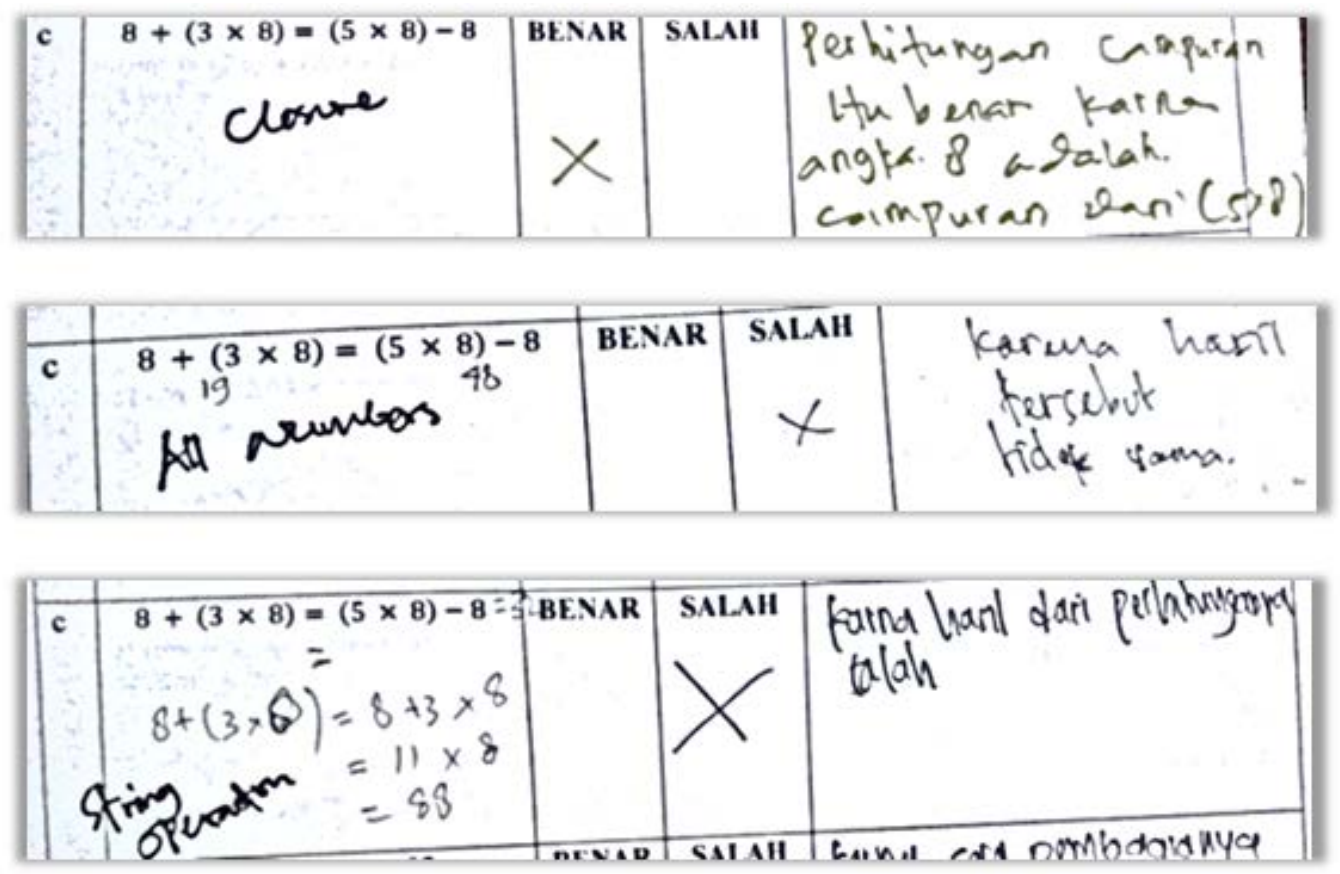

Figure 3. Examples of Students' Misconceptions on Relational Questions 3 

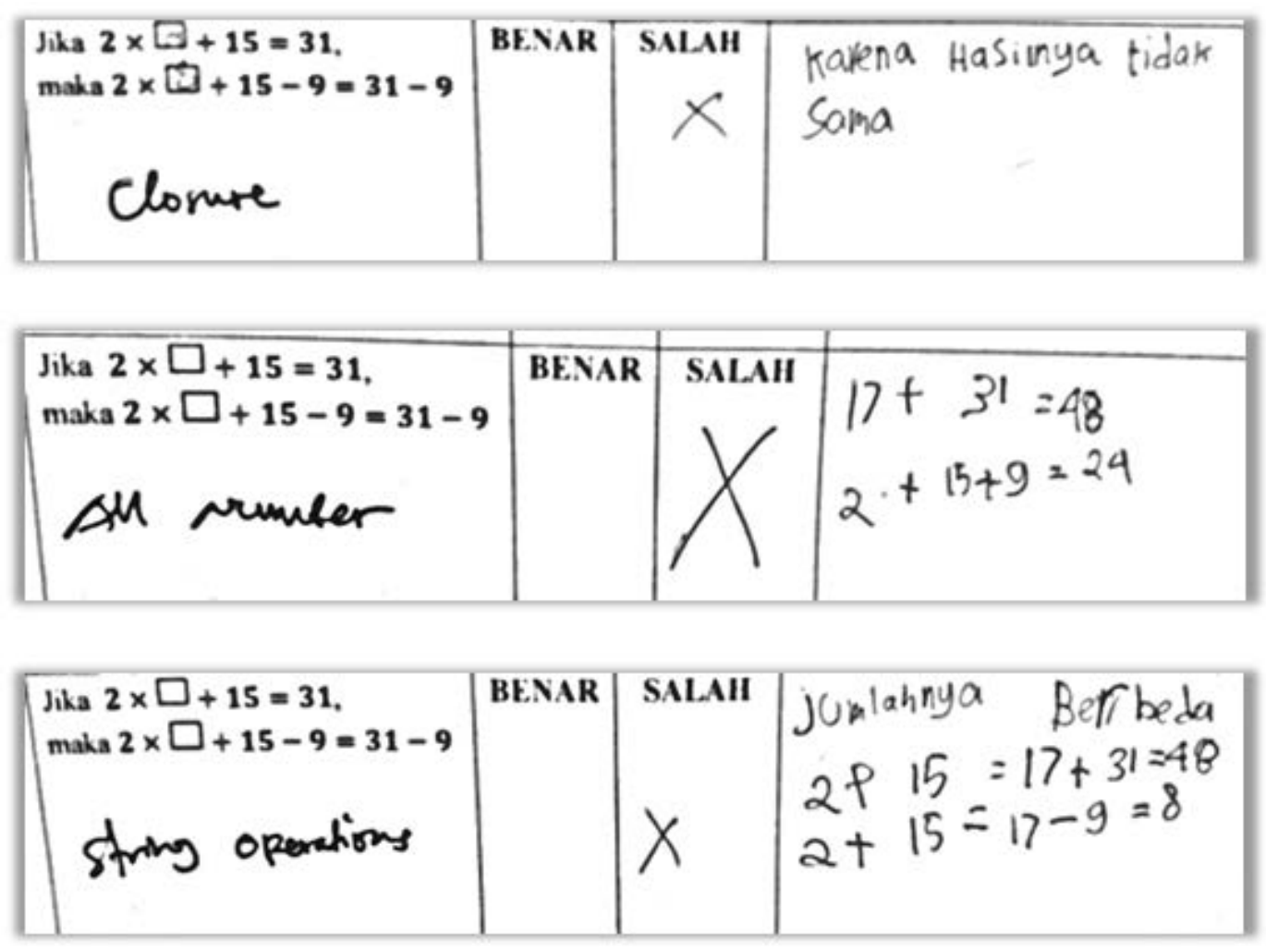

Figure 4. Examples of Students' Misconceptions on Relational Questions 4

The fourth question is given to explore whether students have a conceptual description that the equal sign is a symbol that states the equality relationship on both sides of the equal sign (Kieran, 1981; Knuth, et al., 2006; Mattews, 2010; McNeil, Fyfe, \& Dunwiddie, 2015). The equation in question 4 is a combination problem such as $(a+b=c$ then $a+b-d=c-d$ ) it will be difficult to solve correctly without using at least some sort of arithmetic procedure but it can be solved easily if the student admits that the two expressions on both sides of the sign are equal have the same value. So not all equality problems have the same demands on problem solvers. Combination problems like this are very important to be developed in an effort to help the transition process of students from arithmetic and algebra. When solving algebraic equation problems, students are required to have flexibility in using the equal sign in various contexts and its manipulation. Unfortunately, as question 3, many students also answered arbitrary questions as shown in Figure 4.

When the interview process with grade 6 students with the misconception of 'closure', it became clear that students did not have the concept image of the equal sign other than as a 'counting sign' or 'sign indicating results' as in the interview quotation related to the relational meaning of the equal sign presented in Figure 5.

Researcher: "solve the following problem $10+\square=$ $2+\square$. How did you get the answer? "

Student: " $10+2=12$. So the answer is 12 "

Researcher: "Aren't there two boxes?"

Student: "oh yes"
Researcher: "then what is the value of the other box?" (pointing to the box to the right of the equal sign).

Students: "10"

Researcher: "why 10 ?"

Student: "let the result be 12"

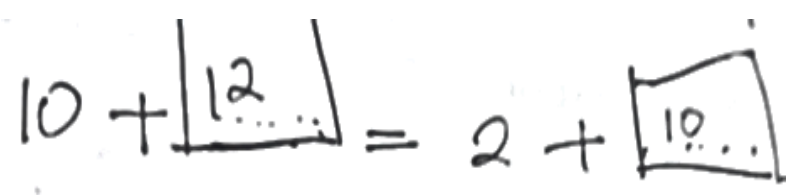

Figure 5. Student's Concept Image of the Relational Meaning of the Equals Sign

The specification category of the equal sign has not been widely investigated by mathematical researchers (e.g, Prediger 2010). Most of the research results only explore two categories, namely operational and relational. Therefore, the findings about students' misconceptions in the specification category are one of the novelties of this study. Category specification in this study is explored through two questions, namely about the definition of the same two sets and an unknown number defined in the sentence of the story. Only four students correctly answered question 1 and no students correctly answered question 2.

Some students with the misconception of 'closure' force themselves to do calculations using members of sets A and $\mathrm{B}$ as shown in Figure 6 students with the misconception of 'using all the numbers in the equation' calculate the number of members of the set as a basis for drawing conclusions. 

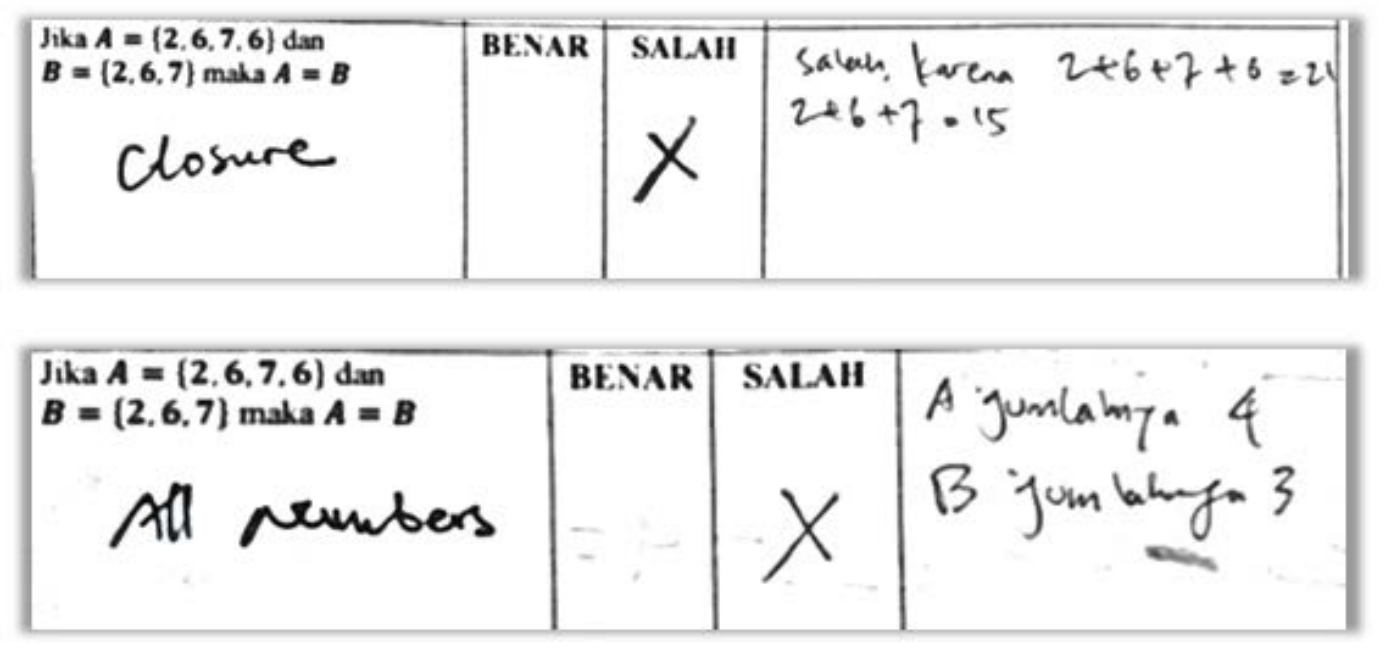

Figure 6. Examples of Students' Misconceptions on Question 1 of Specification

\subsection{Teacher's Concept Image of the Equal Sign}

The researcher gave a questionnaire consisting of 10 questions to explore the teachers' concept image about the equal sign. Of the 10 teachers who were asked to fill out the questionnaire, only 6 returned. They submitted the questionnaire anonymously. The six teachers did not fill in all the questions in the questionnaire, there were some questions that were left blank without answers and the answers appeared to be some of the same among certain class teacher partners. The questions in the questionnaire were divided into three main themes, namely their conceptual description of the equal sign, their learning and teaching experiences about being equal, and identification of students' misconceptions, their causes and efforts to prevent them. The questions on this last theme are left by most of the teachers. All relevant results from the questionnaire are summarized in the tabular format listed in Table 3.

Table 3 shows a summary of the questionnaires that were filled in and returned by the six teachers. The responses given by the teacher generally indicate that the concept image of the equal sign is a sign that shows results, an indication of the operational category. As for a teacher who has been on a relational. From his answers, it is difficult to assume that he had a well-developed relational view. From table 3 it is also clear that the teachers in this study also did not have a deep understanding of the equal sign, so that they did not put special emphasis on a clear definition of the equal sign, and the lack of variation in presenting the equal sign. Therefore, the researcher can assume that the concept of the equal sign representing the relational sign is not considered a basic concept required by students to go beyond a more algebraic way of thinking. In fact, students need to develop a relational understanding of the equal sign to prepare for success in algebra. The term relational thinking introduced by Carpenter, et al. (2003) can provide a basis for learning algebra (or in itself a form of algebraic reasoning) thereby facilitating the transition of students to formal studies of algebra in later grades, thus there is no significant 'distance' between arithmetic and algebra. This type of thinking can make students consider mathematical sentences as a whole and then analyze the structure and important elements of the sentence to produce productive solutions (Molina \& Ambrose, 2008; Stephens \& Ribeiro, 2012).

When explored further during the interview, teachers know that the equal sign is a relational symbol but in their instruction of the concept fail to link the equal sign and equivalence when introducing the concept. The teacher also felt that there was no need to introduce an equal sign specifically because "the equal sign was entered when the teacher taught addition and subtraction operations. Moreover, today's students before entering elementary school already have an understanding of arithmetic ". In addition, they collided with the number of teaching hours and the demands of the curriculum. The books they use in the teaching and learning process in class also do not teach the equal sign in particular. In the interview, the teacher also admitted that students still had conceptual thoughts that showed the same sign as "showing an answer", and what they taught could encourage students' operational views about the equal sign. They are also reluctant to develop a special didactic design that contains didactic-pedagogical anticipation because of the complexity and the large number of learning materials they have to deliver according to the curriculum target. One of the teachers interviewed was unable to identify whether the students' writing indicated errors or misunderstandings as well as possible causes of the misunderstanding. Neither were the teachers able to demonstrate any strategies for how to prevent or reduce students' misunderstanding of the equal sign. 
Table 3. Summary of the Results of the Teachers Questionnaire

\begin{tabular}{|c|c|c|c|}
\hline $\begin{array}{l}\text { Question } \\
\text { Theme }\end{array}$ & Questions & Variations in Teacher's Answers & $\begin{array}{c}\text { Number of } \\
\text { Teachers } \\
\text { Answering } \\
\text { Questions }\end{array}$ \\
\hline \multirow{9}{*}{$\begin{array}{l}\text { Concept } \\
\text { Image of the } \\
\text { Equal Sign }\end{array}$} & \multirow{3}{*}{ What do You think the sign '=' means? } & A sign that indicates the calculation result & 4 \\
\hline & & The similarity of quantity & 1 \\
\hline & & Equivalency & 1 \\
\hline & \multirow{3}{*}{ How would You describe the '=' sign in more detail? } & $\begin{array}{l}\text { Operation similarity of the left with the results } \\
\text { obtained on the right }\end{array}$ & 4 \\
\hline & & The value on the left is equivalent to the right & 1 \\
\hline & & Like the balancing & 1 \\
\hline & \multirow[t]{3}{*}{$\begin{array}{l}\text { Do the words 'same', 'equation' and 'equality' have the } \\
\text { same or different meanings? Provide explanations } \\
\text { and examples of Your answers. }\end{array}$} & $\begin{array}{l}\text { The meaning is different } \\
\text { "Same" simply states the result of the operation. } \\
\text { For example, } 2 \times 2=4 \\
\text { "Equality" has a value that must be adjusted so } \\
\text { that the value of the left side is the same as the } \\
\text { right side. For example } 2 x=20 \text { then the } \\
\text { value of } x \text { must be } 10 \text { to fulfill the equation } \\
\text { "Equation" indicates the value of the same } \\
\text { operation between the left side and the right } \\
\text { side. For example, } 7+3=4+6\end{array}$ & 1 \\
\hline & & $\begin{array}{l}\text { Same: Same meaning, same weight, same } \\
\text { height, etc. } \\
\text { Equations: Aldi and Aldo have the same face } \\
\text { shape because they were born twins } \\
\text { Equality: these two variables can be solved by a } \\
\text { two-variable system of equations }\end{array}$ & 3 \\
\hline & & The meaning is not different & 2 \\
\hline \multirow{5}{*}{$\begin{array}{l}\text { Learning } \\
\text { and } \\
\text { Teaching } \\
\text { Experience } \\
\text { of the Equals } \\
\text { Sign }\end{array}$} & $\begin{array}{l}\text { Have You ever studied the sign "=" from a historical, } \\
\text { semiotic, and philosophical perspective? }\end{array}$ & No & 6 \\
\hline & $\begin{array}{l}\text { What books or study resources do You use to study } \\
\text { the '=' sign? Please state. }\end{array}$ & $\begin{array}{l}\text { Textbook, } \\
\text { Module, } \\
\text { Math textbook used in class } \\
\end{array}$ & 6 \\
\hline & $\begin{array}{l}\text { How did Your teacher at school teach You the '=' sign } \\
\text { in class? }\end{array}$ & Do arithmetic problems & 6 \\
\hline & $\begin{array}{l}\text { Does the learning design that You make before } \\
\text { entering the class consider the didactic-pedagogical } \\
\text { anticipation point of view to optimally encourage } \\
\text { student mental action? }\end{array}$ & $\begin{array}{l}\text { Teaching according to the mathematics } \\
\text { textbook required by the government }\end{array}$ & 6 \\
\hline & $\begin{array}{l}\text { Have You ever taught the equal sign as material that } \\
\text { was specifically discussed to support students } \\
\text { thinking algebra from an early age? }\end{array}$ & No & 6 \\
\hline \multirow{6}{*}{$\begin{array}{l}\text { Identificatio } \\
\text { n of } \\
\text { Students' } \\
\text { Misconcepti } \\
\text { ons, Their } \\
\text { Causes and } \\
\text { Prevention } \\
\text { Efforts }\end{array}$} & \multirow{3}{*}{$\begin{array}{l}\text { Instruction given to student: } \\
\text { Mei-mei bought } 4 \text { apples and } 3 \text { bananas. She } \\
\text { squeezed } 2 \\
\text { apples for juice and ate } 1 \text { banana. How many pieces } \\
\text { of fruit does she have left? } \\
4+3=7-2=5-1=4 \\
\text { A) The student's answer is correct } \\
\text { B) The student's answer is incorrect } \\
\text { C) The answer is correct but the working is incorrect. } \\
\text { Please give Your reason and explain the possible } \\
\text { cause and how to prevent it. }\end{array}$} & Correct & 1 \\
\hline & & Incorrect & 2 \\
\hline & & Not answer & 3 \\
\hline & \multirow{3}{*}{$\begin{array}{l}\text { Instruction given to student: } \\
\text { Fill in the correct answer in the place of the } \Delta \text { : } \\
6+3=\Delta-2 \\
\text { Srudent's response: } 6+3=9-2=7 \\
\text { A) The student's answer is correct } \\
\text { B) The student's answer is incorrect } \\
\text { C) The answer is correct but the working is incorrect. } \\
\text { Please give Your reason and explain the possible } \\
\text { cause and how to prevent it. }\end{array}$} & Correct & 1 \\
\hline & & Incorrect & 2 \\
\hline & & Not answer & 3 \\
\hline
\end{tabular}




\section{Conclusion}

Based on the results reported above, it can be concluded that the concept image of the teacher regarding the equal sign generally seems to the flexible operational category, not yet having a well-developed relational view. Teachers' concept image of the equal sign and how to teach it are often influenced by the textbooks they use, especially if there are no curricular guidelines. This is also supported by the lack of their portion to study mathematics in depth, even not receiving proper and specific training in mathematics, as happened to the teachers in this study. In several studies, both internationally and in Indonesia, it is still widely found that elementary and secondary school mathematics textbooks usually present an equal sign in the context of equations such as $a+b=c$ and rarely in the context of equations of type $a+b=c+d$ (McNeil et al., 2006, Vermeulen \& Meyer, 2017). Therefore, it is not surprising that the teachers show the concept image of the equal sign as a sign indicating the result of an operation.

Some or even all of the combined mathematical problems require quantitative solutions that involve arithmetic operations. Generally children succeed in canonical problems but many children show a misunderstanding of the equal sign symbol for equality which can hinder success in higher mathematics but often goes undetected (Kieran, 1981; Knuth, et al., 2005; McNeil. \& Alibali, 2005; Sherman \& Bisanz, 2009). Textbooks and classroom teaching that always exhibits canonical problems seem to reinforce the notion that the equal sign means identical as providing answers rather than the relational view that both parties are equal (Alibali, 1999; Kieran, 1981; McNeil \& Alibali, 2004, 2005; Seo \& Ginsburg, 2003; Sherman \& Bisanz, 2009). The operational view of the equal sign can make it difficult for the unknown, non-canonical equations such as __ $=2+3$ look wrong, and can hinder understanding of algebra (Carpenter et al., 2003; Kieran, 1981; Knuth et al. ., 2005; Seo \& Ginsburg, 2003; Sherman \& Bisanz, 2009). Students' subjective mental actions require teachers to respond to individual student needs. Therefore, the teacher must be able to identify student misunderstandings and decide on a plan of action to help them resolve them. If these misconceptions are not handled properly, they will cause difficulties in learning mathematics at higher levels such as algebra (Stephens, 2006).

The concept image of the teacher really determines how the quality of the learning design made by them. Even though, the learning design is the main scenario for the teacher in delivering learning material to students. What is taught by the teacher will determine the concept image of students about the learning material. Thus, the concept image of the teacher is the main asset for forming the concept image possessed by students. Learning design that is not sufficient to create a learning environment that supports students' subjective mental action has been proven to lead to the existence of a Zone of Concept Image
Differences (ZCID), namely the gap that occurs between the concept images of students as a result of learning experiences and learning resources that are referred to in learning environment that occurs due to a certain didactic series that is not in accordance with the proper scientific conception (Suryadi, 2019). This qualitative study did not attempt to prove whether there was a statistically significant relationship between teachers' and students' concept images of the equal sign and the existence of the Zone of Concept Image Differences (ZCID). Nonetheless, this study has shown that teachers are generally unaware that their teaching can, and may, indeed, encourage students to misunderstand the equal sign, nor can they identify student misconceptions or suggestions on how to prevent, reduce or correct these misconceptions.

\section{REFERENCES}

[1] Alibali, M.W., et al. (2007). A longitudinal examination of middle school students' understanding of the equal sign and equivalent equations. Mathematical Thinking and Learning, 9(3), 221-247. https://doi.org/10.1080/10986060701360902

[2] Baiduri. (2015). Mathematics education students' understanding of equal sign and equivalent equation. Asian Social Science, 11(25), 15-24. DOI: 10.5539/ass.v11n25p15

[3] Banerjee, R. (2011). Is arithmetic useful for the teaching and learning of algebra?. Contemporary Education Dialogue, 8(2), 137-159. https://doi.org/10.1177/0973184911008002 02

[4] Best, C. T., McRoberts, G. W., \& Goodell, E. (2001). Discrimination of non-native consonant contrasts varying in perceptual assimilation to the listener's native phonological system. Journal of the Acoustical Society of America, 109, 775-794. http://dx.doi.org/10.1121/1.1332378

[5] Blanton, M.L. (2008). Algebra and the elementary classroom: transforming thinking, transforming practice. New York: Heinemann.

[6] Bruner, J. S. (1957). On perceptual readiness. Psychological Review, (64)2, 123-152. http://dx.doi.org/10.1037/h004380 5

[7] Carpenter, T. P., Franke, M. L., \& Levi, L. (2003). Thinking mathematically: integrating arithmetic and algebra in elementary school. Portsmouth, New Hampshire: Heinemann.

[8] Carpenter, T.P., Levi, L., Franke., M.L., \& Zeringue, J.K. (2005). Algebra in elementary school: Developing relational thinking. ZDM, 37(1), 53-59

[9] Darr, C. (2003). The meaning of “equals". Professional Development, 2, 4-7. https://doi.org/10.1080/18117295.201 7.1321343

[10] Denmark, T., Baxco, E. \& Voran, J. (1976). Final report: A teaching experiment on equality, PMDC Technical Report No. 6, Florida State University

[11] Du Plooy-Cilliers, F., Davis, C., \& Bezuidenhout, R. (Eds) 
(2014). Research Matters. Paarl: Juta.

[12] Jones, I., et al. (2012). Substitution and sameness: Two components of a relational conception of the equals sign. Journal of Experimental Child Psychology, 113(1), 166-176. http://dx.doi.org/10.1016/j.jecp.2012.05.003

[13] Falkner, K.P., Levi, L., Carpenter, T.P. (1999). Children's understanding of equality: a foundation for algebra. Teaching Children Mathematics, 6(4), 232-236. http://www.jstor.org/stable/41197398

[14] Filloy, E. \& Rojano, T. (1989). AssociationSolving Equations: The Transition from Arithmetic to Algebra. For the Learning of Mathematics, 9(2), 19-25. http://www.jstor.org/stable/40247950

[15] Flege, J. E., Yeni Komshian, G. H., \& Liu, F. (1999). Age constraints on second-language acquisition. Journal of Memory and Language, 41, 78 - 104

[16] Fuchs, L.S. et al. (2014). Does calculation or word-problem instruction provide a stronger route to pre-algebraic knowledge?. Journal of Educational Psychology, 106(4), 990-1006. http://dx.doi.org/10.1037/a0036793

[17] Harel, G. (2008). What is Mathematics? A Pedagogical Answer to a Philosophical Question. In B. Gold \& R.A Simons (Eds.), Proof and other Dilemmas: Mathematics and Philosopy (pp. 265-290). The Mathematical Association of America.

[18] Hattikudur, S., \& Alibali, M.W. (2010). Learning about the equal sign: does comparing with inequality symbols help?. Journal of Experimental Child Psychology, 107, 15-30

[19] Kieran, C. (1981). Concepts associated with the equality symbol. Educational Studies in Mathematics, 12, 317-326. https://doi.org/10.1007/BF00311062

[20] Kilpatrick, J., Swafford, J., \& Findell, B. (eds.). 2002. Adding it up. helping children learn mathematics. Washington, DC: National Academy Press.

[21] Kindrat, A.N., \& Osana, H.P. (2018). The relationship between mental computation and relational thinking in the seventh grade. Fields Mathematics Education Journal, 3(6), 1-22. https://doi.org/10.1186/s40928-018-0011-4

[22] Kiziltoprak, A \& Kose, N.Y. (2017). Relational thinking: the bridge between arithmetic and algebra. International Electronic Journal of Elementary Education, 10(1), 131-145 10.26822/iejee.2017131893

[23] Knuth, E.J, et al. (2006). Does understanding the equal sign matter? Evidence from solving equations. Journal for Research in Mathematics Education, 36, 297-312. DOI: $10.2307 / 30034852$

[24] Knuth, E.J., et al. (2008). The importance of equal sign understanding in the middle grades. Mathematics Teaching in the Middle School, 13(9), 514-519

[25] Li, X., Ding, M., Capraro, M. M., \& Capraro, R. M. (2008). Sources of differences in children's understandings of mathematical equality: Comparative analysis of teacher guides and student texts in China and the United States. Cognition and Instruction, 26, 195-217. http://dx.doi.org/10.1080/07370000801980845

[26] Mann, R.L., (2004). Balancing Act: The Truth behind the Equals Sign. Teaching Children Mathematics, 11(2), 65-69. http://www.jstor.org/stable/41198439

[27] Mattews, P.G., et al. (2010). Understanding the equals sign as a gateway to algebraic thinking. SREE, 1-6

[28] Matthew, P., Rittle-Johnson, B., McEldoon, K. \& Taylor, R. 2012. Measure for measure: what combining diverse measure reveals about children's understanding of the equal sign as an indicator of mathematics equality. Journal for Research in Mathematics Education, 45(3):316-350.

[29] McNeil, N.M., \& Alibali, M.W. (2004). You'll see what you mean: Students encode equations based on their knowledge of arithmetic. Cognitive Science, 28, 451-466. doi:10.1016/j.cogsci.2003.11.002

[30] McNeil, N.M., \& Alibali, M.W. (2005). Why won’t you change your mind? knowledge of operational patterns hinders learning and performance on equations. Child Development, 76(4), 883 - 899. http://dx.doi.org/10.1111/j. 1467-8624.2005.00884.x

[31] McNeil, N.M., et al. (2006). Middle-school students understanding of the equal sign: the books they read can't help. Cognition and Instruction, 24(3), 367-385. https://www.jstor.org/stable/27739839

[32] McNeil, N.M., et al. (2011). Benefits of practicing $4=2+2$ : Nontraditional problem formats facilitate children's understanding of mathematical equivalence. Child Development, 82(5), 1620-1633. DOI: 10.1111/j.1467-862 4.2011.01622.x

[33] McNeil, N.M., Fyfe, E.R., \& Dunwiddie, A.E. (2015) Arithmetic practice can be modified to promote understanding of mathematical equivalence. Journal of Educational Psychology, 107(2), 423-436. http://dx.doi.org/10.1037/a0037687

[34] Meyer, B. C. (2016). The equal sign: teachers' specialised content knowledge and learners' misconceptions. A thesis. Not published.

[35] Mirin, A. (2019). The relational meaning of the equals sign: a philosophical perspective. Paper presented at the meeting of the 22nd Annual Conference of the Special Interest Group of the Mathematical Association of America on Research in Undergraduate Mathematics Education, Oklahoma City, USA

[36] Molina, M. \& Ambrose, R. (2008). From an operational to a relational conception of the equal sign. Thirds graders' developing algebraic thinking. Focus on Learning Problems in Mathematics, 30(1), 61-80.

[37] Oksuz, C. (2007). Children's understanding of equality and the equal symbol. International Journal for Mathematics Teaching and Learning, 1-19

[38] Prediger, S. (2010). How to develop mathematics-for-teaching and for understanding: the case of meanings of the equal sign. Journal of Mathematics Teacher Education, 13(1), 73-93. DOI 10.1007/s10857-009-9119-y

[39] Radford, L. (2000). Signs and meanings in students' emergent algebraic thinking: a semiotic analysis. Educational Studies in Mathematics, 42(3), 237-268

[40] Rittle-Johnson, B., et al. (2010). Assessing knowledge of mathematical equivalence: a construct-modeling approach. Journal of Educational Psychology, 1-20. DOI: 


\subsection{7/a0021334}

[41] Risch, M.R. (2014). Investigation about representations used in teaching to prevent misconceptions regarding inverse proportionality. International Journal of Science, Technology, Engineering and Math Education. 1(4),1-7.

[42] Rumelhart, D. E. (1980). Schemata: The building block of cognition. In R. Spiro, B. Bruce, \& W. Brewer (Eds.), Theoretical issues in reading comprehension (pp. 33-58). Hillsdale, NJ: Lawrence Erlbaum.

[43] Sáenz-Ludlow, A., \& Walgamuth, C. (1998). Third graders' interpretations of equality and the equal symbol. Educational Studies in Mathematics, 35(2), 153-187

[44] Seo, K.-H., \& Ginsburg, H. P. (2003). "You've got to carefully read the math sentence. .'”: Classroom context and children's interpretations of the equals sign. In A. J. Baroody \& A. Dowker (Eds.), The development of arithmetic concepts and skills (pp. 161 -187). Mahwah, NJ: Erlbaum

[45] Sewell, A. (2002). Constructivism and students' misconceptions: Why every teacher needs to know about them. Australian Science Teachers Journal, 48(4), 24-28.

[46] Sherman, J., \& Bisanz, J. (2009). Equivalence in symbolic and nonsymbolic contexts: benefits of solving problems with manipulatives. Journal of Educational Psychology, 101(1), 88-100. DOI: 10.1037/a0013156

[47] Stephens, A. C., et al. (2013). Equation structure and the meaning of the equal sign: The impact of task selection in eliciting elementary students' understandings. Journal of Mathematical Behavior, 32, 173- 182. http://dx.doi.org/10. 1016/j.jmathb.2013.02.001

[48] Stephens, M., \& Ribeiro, A. (2012). Working towards algebra: the importance of relational thinking. Revista Latinoamericano de Investigacion en Matematica Educativa, 15(3), 373-402.

[49] Suryadi, D. (2019). Landasan Filosofis Penelitian Desain Didaktis (DDR). Gapura Press : Bandung

[50] Tall, D., \& Vinner, S. (1981). Concept image and concept definition in mathematics with particular reference to limits and continuity. Educational Studies in Mathematics, 12, 151-16.

[51] Tilley, V. (2011). Two little lines. Mathematics Teaching. Published in September. 19-24.

[52] Vermeulen, C., \& Meyer, B. (2017). The equal sign: teachers' knowledge and students' misconceptions. African Journal of Research in Mathematics, Science and Technology Education, 21(2), 136-147 